\title{
Group Treatment Strategies in Juvenile Correctional Programs*
}

\author{
ROSEMARy C. SARrI \\ Associate Professor, School of Social Work, University of Michigan \\ B.A., 1946, M.S.W., 1955, University of Minnesota; Ph.D. (Sociology and \\ Social Work), 1962, University of Michigan \\ ROBERT D. VINTER \\ Associate Dean and Professor of Social Work, School of Social Work, \\ University of Michigan \\ A.B. (Psychology), 1943, Trinity College; M.S.W., 1947, Columbia University
}

School of Social Work; Ph.D. (Social Psychology), 1957, Columbia University

Direct and indirect approaches to group intervention recently utilized by juvenile correctional agencies, including closed institutions, minimum security or work camps, courts, and detached worker and street-gang programs in open community agencies, are examined to identify their distinguishing features and to assess their usefulness.

Direct group methods are classified into three categories: group education, group counseling, and group therapy. Indirect methods are divided into institutional management and milieu treatment. Each method is examined with reference to variables relevant to the entire range of treatment: goals, change targets and program focus, client characteristics, staff characteristics and role patterns, and evaluation of outcomes.

Since each approach presents certain advantages when employed appropriately and when integrated into a larger agency strategy, the paper suggests conditions which might determine the effectiveness of any selected approach. Mentioned here are the necessity of specification of individual change goals, the use of peer groups as a means for change, the selection of properly trained personnel, and the integration of services within an agency.

- An earlier version of this paper was presented at the 90th Annual Forum, National
Conference on Social Welfare, May 24, 1963, and at the 72nd Annual Meeting, Ohio Welfare Conference, October 1962, Cincinnati. 
$\mathbf{T}$ THE BASIC TASK of correctional services for juvenile offenders is to resocialize clients whose behavior and values deviate from those which are legally and socially acceptable. A principal problem for all correctional agencies and other organizations responsible for changing people is that of devising effective and efficient methods for causing change and for stabilizing it beyond the period of agency service. ${ }^{1}$

New means of treatment are sought by personnel in all of these organizations, who have become increasingly dissatisfied with traditional methods and increasingly skeptical of the bahavioral theory that most offenders are emotionally maladjusted and, therefore, in need of intensive individual therapy. Sociologists who have studied the interpersonal dynamics of juvenile delinquency stress that there must be intervention in the deviant subculture or peer group for successful rehabilitation to be attained. ${ }^{2}$

1 See R. D. Vinter, "The Analysis of Treatment Organizations," Social Work, July 1963, pp. 3-15; and M. Zald, "The Correctional Institution for Juvenile Offenders: An Analysis of Organizational Character," Social Problems, Summer 1960, pp. 57-63.

2 See R. Cloward, et al., Theoretical Studies in Social Organization of the Prison (New York: Social Science Research Council, 1960); L. E. Ohlin and W. E. Lawrence, "Social Interaction among Clients as a Treatment Problem," Social Work, April 1959, pp. 3-13; H. Polsky, Cottage Six (New York: Russell Sage Foundation, 1962); and A. K. Cohen, Delinquent Boys: The Culture of the Gang (Glencoe, Ill.: Free Press, 1955) . Attention in this paper is focused on correctional programs for juveniles, but it is our observation that similar problems are faced i11 adult correctional settings. The latter agencies may be more seriously disabled in their rehabilitative efforts because of the powerful countereffects of informal inmate social relations built around values and norms of solidary opposition to the official system.
Everywhere we see a heightened appreciation for the potentials of the small group and the development of new tactics for realizing these potentials through group treatment procedures.

In this paper we will describe and examine some of the group methods employed in correctional agencies. ${ }^{3}$ Although not meant to be comprehensive, this review will analyze methods offered in a variety of agency contexts including closed institutions, minimum security or work camps, courts, and detached worker and street gang programs of open community agencies. Our attention will be confined to utilization of the group for explicit treatment purposes, ignoring its many other uses for recreational, academic, work, or dormitory purposes.

\section{Direct Group Methods}

There are two principal methods of group treatment, direct and indirect. The former includes group education, group counseling, and several types of group therapy. Indirect or social milieu methods include institutional management and other forms of environmental manipulation. ${ }^{4}$

3 More than 110 publications on group treatment approaches were reviewed in the preparation of this paper, with particular emphasis given to the $1955-63$ period. No attempt was made at a comprehensive review; nevertheless, the relatively large number of publications included provides a reasonable basis for tentative judgments about group treatment methods.

4 For comparative and analytic purposes it was necessary to draw distinctions among the several types of group treatment methods. For example, the same author may refer to a given program as both group counseling and group therapy. We recognize that the distinctions which we have drawn are arbitrary and do not represent a consensus about the appropriate nomenclature to be used in defining group treatment approaches. 
Among direct methods, the use of groups for educational purposes appears to have existed longest in the correctional field. In this category are orientation programs to communicate policies and rules to clients, classes in social adjustment, citizenship training, and parent education. Techniques employed are largely didactic with little or no concern for clients' attitudes and specific problems, since it is assumed that they have a common need for acquiring the general instructional content.

The second category of direct methods, "group counseling," is the method most frequently referred to in reports of group treatment. The service is typically provided to formally composed client groups ranging in size from five to fifteen members and directed by lay or nonprofessional staff. 5

Included in the third category, "group therapy," are group psychotherapy, social group work, and "guided group interaction," all of which are typically utilized for smaller groups of clients. Although group therapy and group counseling have overlapping goals, the most significant difference between the two appears to be the training of personnel who render the service: we include under group therapy only those services provided by professionally trained personnel - psychiatrists, psychologists, and social workers. Further, through

5 See N. Fenton, et al., Explorations in the Use of Group Counseling in the County Correctional Program (Palo Alto, Calif.: Pacific Books, 1962), for a discussion of group counseling programs in California. Staff members generally are not professionally trained; instead, selected personnel receive brief but intensive in-service training and continuing supervision from professional staff. Group counseling services are offered in both institutional and community settings. review of the literature, certain basic differences among the group therapies can be identified. Group psychotherapy is most frequently directed toward intrapsychic or personality change, the development of insight, and so forth. ${ }^{6}$ The group is viewed primarily as a special context for treatment, and the crucial relations are those between the therapist and each client. Social group work and guided group interaction, however, are directed more toward attitudinal and behavioral changes, and the group is viewed as both a means and a context for treatment. ${ }^{7}$ Thus, in the latter approaches there is more explicit concern with group phenomena and the manipulation of conditions within the group so that it can act as a potent influence toward change for its members.

\section{Social Milieu Approaches}

Social milieu approaches have recently come to the correctional field from the "therapeutic milieu" concept, developed in residential treatment of the mentally ill. In this area a distinction must be made between institutional management and milieu treatment: in the former, selected aspects of institutional organization and

6 See L. D. Penny, "Group Psychotherapy with Boys," Proceedings of the National Association of Training Schools and Juvenile Agencies, 1959, pp. 178-84.

7 For a discussion of social group work practice principles, see $\mathbf{R}$. D. Vinter, "The Essential Components of Social Group Work Practice" (Ann Arbor: University of Michigan School of Social Work, 1959, mimeo.), and G. Konopka, "The Social Group Work Method: Its Use in the Correctional Field," Federal Probation, March 1956, pp. 25-30. See L. McCorkle, A. Elias, and F. L. Bixby, The Highfields Story (New York: Henry Holt, 1958); and L. Empey and J. Rabow, "The Provo Experiment in Delinquency Rehabilitation," American Sociological Review, October 1961, pp. 679-96, for discussions of guided group interaction. 
routine are involved, whereas, in the latter, the manipulation of the total environment is sought. Polsky, Grosser, and Ohlin and Lawrence have emphasized the importance of apprehending the various ways in which social forces and environmental factors within the institutions often operate to negate direct treatment methods.8 Some correctional institutions have drastically altered certain of their modes of operation to permit greater manipulation of environmental factors in the interest of treatment; for example, by reassigning professional staff, such as social workers, to positions where they have direct responsibility for cottage life and can exploit all aspects of the living unit. Our own research has documented some of the problems encountered in such total manipulation and some of the disadvantages when it is not achieved.9

Social milieu methods in community agencies include efforts to modify agency structure or local neighborhood and community conditions so that they will be supportive of treatment goals. The importance of these factors has long been emphasized, but little demonstrable success has been achieved. ${ }^{10}$

8 See G. Grosser, "The Role of Informal Inmate Groups in Change of Values," Children, January-February 1958, pp. 25-29; Polsky, op. cit. supra note 2; and Ohlin and Lawrence, supra note 2.

9 R. Vinter and M. Janowitz, et al., The Comparative Study of Juvenile Institutions: A Research Report (Ann Arbor: University of Michigan, 1961).

10 For a review of community delinquency programs in which various environmental factors have been considered see $M$. Gold and J. A. Winter, $A$ Selective Review of Community-Based Programs for Preventing Delinquency (Ann Arbor: Institute for Social Research, October 1961); see also R. K. Merton, "The Social-Cultural Environment

\section{Group Treatment Patterns and Variables}

It is difficult to assess the extent to which group treatment methods in correctional agencies are actually being employed today, because, although there is a relatively extensive literature on many aspects of the subject, little systematic information has been reported about the quantity, types, and quality of services. The only general facts are those reported in the McCorkle and Elias survey of all public correctional institutions in the United States in 1950 and again in 1959." McCorkle and Elias sought to determine the extent of use of group therapeutic methods, but they did not explicitly define group therapy and left the respondents free to decide which treatment methods they chose to report.

The type of treatment most frequently reported was defined as "group counseling." During the 195059 decade it appeared to have become the principal treatment method in nany institutions. Only one-third of the institutions reported that group treatment was conducted by psychiatrists, psycholngists, or trained social workers. Instead, administrators relied largely on nonprofessional staff, who received in-service training in group methods.

McCorkle and Elias found no definitive patterns with respect to the types of clients chosen for group treat-

and Anomic," in H. L. Witmer and R. Kotinsky (eds.). New Perspertives for Research on Juvenile Delinquency (Washington, D. C.: Children's Bureau Publication No. 356, 1956), pp. \$2-33.

11 For results of two surveys of group treatment in jur inile correctional institutions, see L. McCorkle and A. Elias, "Group Therapy in Correctional Institutions," Federal Probation, June 1959, pp. 57-63. 
ment, and seldom any uniform provision of it for all clients. Sixty per cent of the institutions reported five or fewer therapy groups. Although institutional personnel seemed concerned about outcomes, less than onefifth of the institutions made any effort to evaluate group treatment programs objectively.

The use of group treatment methods has expanded even further since the publication of the McCorkle and Elias study. However, administrators are now seeking more definitive statements about the utility of various methods of group treatment with different types of offenders and in varied agency contexts so that more rational selection of treatment methods can be made.

We will now proceed with a comparative analysis of some group treatment strategies. In examining each approach we will consider certain variables relevant to the entire range of group treatment: goals, change targets and program focus, client characteristics, staff characteristics and role patterns, and evaluation of outcomes.

\section{Comparative Group Strategies}

\section{Group Education}

When the "training school" philosophy was dominant, group educational methods were used extensively because the principal goal was to train offenders in obedience and socially approved behavior. Vestiges of this philosophy remain today in orientation programs, in citizenship training, and occasionally in parent education groups. ${ }^{12}$

Because the task of group education is perceived as one which involves the

12 Similarities are apparent in group orientation programs in correctional institutions and the indoctrination of soldiers in basic training. imparting of specific information, differences in client characteristics and group size are relatively unimportant. Clients often see little connection between the group sessions and their own life situations. Seldom is there any explicit concern with the mobilization of group forces, and interactional processes are not utilized to achieve or sustain changes in clients' attitudes and behaviors.

Staff characteristics and training are of minimal concern; only training in content sufficient to give the requisite instruction is required. Group educational approaches are seldom effective because little attention is given to motivating clients toward the desired change goals. Frequently, informal client relations are forcibly suppressed, with such undesirable consequences as social alienation or, in an inmate system, solidary opposition to staff goals.

Schein's descriptive analysis of indoctrination programs in Chinese Communist prisoner-of-war camps highlights some of the consequences of a comprehensive group educational program employing physical and social force to attain its ends. ${ }^{13}$ Schein suggests that there are important similarities between those camps and juvenile correctional services which have implications for treatment organizations.

\section{Group Counseling}

Group counseling is probably the most prevalent group treatment approach in institutional settings and juvenile court programs. ${ }^{14}$ A wide

13 See E. H. Schein, "Interpersonal Com munication, Group Solidarity and Social Influence," Sociometry, June 1960, pp. 148-61; see also Schein, et al., Coercive Persuasion (Cambridge: Massachusetts Institute of Technology, 1960).

14 At least one state has dereloped an ex- 
range of activities is incorporated under the label. The service is provided by various staff members, professionally trained and otherwise, depending upon agency goals and organizational structure. Two general goals seem to characterize group counseling services: positive group support and re-education. The diversity of approach becomes apparent when we examine the more specific objectives, which include (1) providing information about the agency and its purposes; (2) assisting clients in the perception and acceptance of social reality; (3) encouraging fuller expression of feelings and attitudes; (4) providing positive group experiences and meaningful interpersonal relations with peers and adults; (5) enhancing the self-esteem of the clients.

Although all of these may be stated as objectives for a given group, reports from practitioners suggest that in actuality certain objectives are emphasized arbitrarily, without regard to clients' particular characteristics and situations. Again, as we noted in educational groups, there is an assumption that the goals and content of the approach are appropriate for all clients. Group counseling has been tried in a variety of settings and with a variety of clients. We have, however, little information about the relative effectiveness of this method for certain types of clients, since client characteristics, although identified, have not been used as controls in evaluating outcomes. Several practitioners suggest that group counseling is more

tensive program of group counseling in community and institutional settings for both adults and juveniles. The majority of the personnel are untrained, but receive in-service training and supervision from psychiatrists, psychologists, and social workers. See Fenton, et al., op. cit. supra note 5. effective with clients already able to communicate effectively and with first or minor offenders; however, such assertions are generally based on subjective evaluations. Furthermore, the goals pursued by nonprofessionals tend to be relatively superficial and diffuse, while the techniques tend to be overly specific. Much emphasis is placed on detailed consideration of techniques to be employed by the worker, and outlines of strategy frequently resemble a cookbook!

Counseling groups range in size from eight to ten members, and they meet at least once a week. Where the service is provided by nonprofessional personnel, the period of treatment is relatively brief, averaging less than four months. In contrast, professionally trained workers generally report service of a year or more. ${ }^{15}$

Positive results from group counseling programs directed by nonprofessionals have been reported. Where there has been systematic evaluation, however, the results have been disappointing, if comparisons are made with group therapy programs or professional group counseling.

Walker, Vogt, and others have emphasized the importance of clear delineation of the worker's role and goals. ${ }^{16}$ They are in general agreement that the service must be rendered by a professional worker capable of integrating his dual status as authority figure and treatment agent. They also point to the necessity of defining goals

$15 \mathrm{~V}$. Lincoln, "Group Counseling with Girls," Proceedings of the National Association of Training Schools and Juvenile Agen. cies, 1959, pp. 170-77.

16 See G. J. Walker, "Group Counseling in Juvenile Probation," Federal Probation, December 1959, PP. 31-38; H. Vogt, "Group Counseling in Probation," Federal Probation, September 1961, pp. 49-54. 
in terms of those specific attitudes and behaviors directly relevant to the client's life outside the group. Walker emphasizes group discussions which are "feeling-centered and problemsolving" and the creation and maintenance of a nutrient atmosphere for sharing common problems, but he directs little attention to exploitation of the treatment potential of the group. The difficulty in group counseling is the tendency to seek changes in the attitudes or behavior of the client which have little connection with, or only tangential relevance to, his immediate life situation and his behavior in the community.

\section{Group THERAPY}

The third type of direct group treatment was designated as "group therapy." Included in this category are group psychotherapy, "guided group interaction," and social group work. The principal basis for distinguishing between these and other methods is that the service is rendered by a professionally trained persona psychiatrist, a social worker, or a psychologist-an arbitrary distinction but useful for discussion. A second major difference is in the nature of the goals sought for individual clients.

Group Psychotherapy.-Group psy. chotherapy is probably the oldest of the group therapeutic methods used in correctional settings, although all are of recent origin. Initially it was adapted, as a treatment procedure for juvenile offenders, from clinical practices in mental health agencies. This transfer led to a perception of delinquents as emotionally disturbed. Thus emphasis was placed on the resolution of psychic disorders while sociological factors were largely ignored. ${ }^{17}$

17 For discussions of group psychotherapeutic methods in correction, see $\mathbf{R}$. Geerts-
Although many authors assert that group psychotherapeutic methods bring positive outcomes for certain types of clients, Grosser and others have argued that these methods are inappropriate for the treatment of most delinquents. ${ }^{18}$ They believe that the genesis of delinquency is identification with a subculture whose values deviate from those of the larger society. Therefore, to foster integration into the peer group or to help the delinquent overcome a sense of isolation is not a crucial rehabilitative task.

In individual psychotherapy the central importance of the therapistclient relationship is emphasized; even in group psychotherapy, this relationship remains the principal means of treatment, with the other participants serving primarily as facilitating agents. The literature reveals no recognition of group forces and other conditions which can be modified to enhance treatment effects. Events occurring within the therapeutic session are viewed as the important ones, while outside events are viewed as significant only insofar as

ma, "Group Therapy with Juvenile Probationers and Their Parents," Federal Probation, March 1960, pp. 46-52; M. Hersko, "Group Psychotherapy with Delinquent Adolescent Girls," American Journal of Orthopsychiatry, January 1962, pp. 117-23; H. A. Illing, "Group Psychotherapy and Group Work in Authoritarian Settings," Journal of Criminal Law, Criminology, and Police Science, November-December 1957, pp. 387. 93; A. B. Smith, L. Berlin, and A. Bassin "Group Therapy with Adult Probationers," Federal Probation, September 1956, pp. 15. 21; N. Tolman, "Approaching the Institutionalized Female through Group Therapy," Federal Probation, June 1961, pp. 34-40; and Penny, supra note 6.

18 See Grosser, supra note 8; and $D . R$. Cressey, "Contradictory Theories in Correctional Group Therapy Programs," Federal Probation, June 1954, pp. 20-26. 
they provide material for analysis. If, as Ohlin and Lawrence suggest, a crucial problem in the treatment of delinquents is that of devising a treatment approach which can bring about the strongest adherence to conventional values, traditional group psychotherapy is certainly not the most expeditious strategy. ${ }^{19}$ Many practitioners have recognized some of its inadequacies and subsequently modified certain traditional elements. Unfortunately, few of these modifications have involved goals or basic processes or anything other than mere techniques. The focus is still on the development of insight, the ability to form relationships, and the resolution of internal conflicts.

In a recent study of correctional institutions, we observed that group psychotherapy contributed little to attainment of change goals and, indeed, that it actually increased negative client attitudes toward these goals and the staff. ${ }^{20}$ Our findings suggest some of the reasons why this program was not effective. First, therapists interacted with client members of their groups almost exclusively in the therapy section, where relations were structured and formalized. Second, the content of group sessions was unrelated to daily life or to the problems of clients as they perceived them. Third, the group served only as a context for therapist-client exchanges; there was no attempt to mobilize its forces to achieve client change. Fourth, the group experiences did not facilitate meaningful interpersonal rerelationships relevant to other aspects of institutional life.

Some practitioners who have modi-

19 Ohlin and Lawrence, supra note 2.

20 Vinter and Janowitz, et al., op. cit. supra note 9 . fied basic features of the psychotherapeutic process report quite different results. Geertsma states that the development of insight becomes a secondary aim and successful intervention occurs when the group develops into an effective means for dealing with attitudes toward authority, discipline, school, adolescent culture, and adult society. ${ }^{21}$ As participants reach agreement about appropriate problem areas for transaction, the group becomes a strong instrument of social control and serves to enforce behavioral conformity to group norms and standards. Geertsma suggests that if group therapy is to engage the members effectively, the worker must deliberately concern himself with the creation of those group conditions which facilitate interaction and allow effective social controls to develop.

Guided Group Interaction. - The Highfields Project and the Provo Experiment, experimental group treatment programs that have recently evoked much interest and discussion, ${ }^{22}$ were formulated on the basis of assumptions quite different from the methods we have considered. The principal treatment technique, guided group interaction, was developed in an attempt to apply a sociological theory of delinquency to treatment. We will examine the Provo program, which is similar to that of Highfields but involves an additional element, the provision of supportive help after a period of intensive treatment.

Essential to the Provo program is the assertion that effective intervention must encompass the total social system in which treatment operates.

21 See Geertsma, supra note 17.

22 See McCorkle, Elias, and Bixby, op. cit. supra note 7; and Empey and Rabow, supra note 7 . 
Since delinquency is viewed primarily as a group phenomenon, the task of rehabilitation becomes one of using the group to change shared delinquent values and attitudes. Juvenile offenders in small groups experiment with new modes of behavior and make decisions about one another, their peers, and their families. ${ }^{23}$ Empey and Rabow assert that an effective treatment program must involve the decisionmaking process utilized by the delinquent in his usual community environment.

Some sociological theorists assert that delinquency is a normal adaptive response to an environment where deviant values are supported. In contrast, Empey and Rabow agree with those who suggest that delinquents have been socialized in a culture dominated by a middle-class morality, that they are aware of conventional standards, and that they are ambivalent about their delinquent behavior, maintaining numerous rationalizations by which to "neutralize" it.24 This ambivalence, Empey and Rabow believe, may be used as a vehicle for effecting change, through a program which makes conventional and delinquent alternatives clear and leads offenders to question the utility of their deviant behavior and to perceive for themselves the value of conventional alternatives.

In this approach, change is sought through involving the members in an intensive group experience which is

23 Clients in the Provo program are "habitual" offenders, fifteen to seventeen years old, who are randomly assigned by the court from two categories of offenders: those as. signed for probation and those assigned for commitment to the state training school.

24 G. Sykes and D. Matza, "Techniques of Neutralization: A Theory of Delinquency," American Sociological Review, December 1957, pp. 664-69. specifically focused on the analysis of individual members' problems and, secondarily, on work habits and work performance in conventional jobs. There are few formal demands on clients other than that they appear daily for work on their jobs and participate in the group sessions. The ambiguity resulting from the lack of clear-cut requirements produces anxiety among clients, causing them to turn to the group for help. The peer group is expected to help each boy solve his problems, establish sanctions for his behavior, enforce these sanctions, and help decide such matters as the date of his release. The staff and other officials retain residual authority to be exercised if the client does not involve himself in the group, or if the group is unwilling or unable to handle a situation. Clients are presented with the alternative of participation in this entire experience or transfer to the state training school. During a subsequent period of supportive involvement the client continues to meet occasionally with his group, and efforts are made to help him secure regular employment or further education.

The explicit goals of the Provo program are (1) to juxtapose clearly for clients socially approved and delinquent behavioral alternatives, (2.) to induce them to question the utility of delinquent alternatives, and (3) to guide them toward identification with socially approved values and norms. The peer group is the primary change target, and the program relies on the use of group discussion, informal client interaction, and jobs as vehicles for changing attitudes, values, and work habits. Integral to the total experiment is a five-year systematic evaluation and a comparison with a control group composed of clients as- 
signed to other conventional types of correctional treatment programs.

Of all the treatment methods discussed thus far, "guided group interaction," as exemplified in the programs at Highfields and Provo, represents the most thoroughgoing attempt to grant authority and autonomy to the peer group and to use it explicitly as the primary agent of treatment. It is also distinguishable from other methods in its deliberate attempt to create ambiguity and induce anxiety.

Incomplete knowledge of certain aspects of the Provo program handicaps our analysis of it. Empey and Rabow describe the role of the practitioner, but provide insufficient or inconsistent information about exactly what he does with clients, individually and in the group, during the entire period of treatment. ${ }^{25}$ Furthermore, we question whether a peer group can sustain itself over a period of several months as an effective rehabilitative tool without the contin. uous active intervention of the practitioner.

Despite these uncertainties, this strategy highlights three very important elements in any group treatment program. First, there must be concern about the total system of treatment. Second, the peer group can be exploited as an effective treatment agent. Third, clients' attention must be directed toward dealing realistically with the social environment in which they live and work.

Social Group Work.-During the past decade, social group work in ju-

25 A somewhat more detailed description of the role of the worker is contained in the Highfields report, but even there it is difficult to ascertain the patterns of his intervention. See McCorkle, Elias, and Bixby, $o p$. cit. subra note 7 . venile correctional programs has developed markedly. The rise in the number of professionally trained group workers in correctional settings has been accompanied by clarification of this treatment approach. Although group workers are also employed in closed institutions, work camps, and juvenile courts, we will examine the "detached worker" or "street gang" program since this setting provides some contrast to the types of agencies considered thus far. Agencies and workers in "street gang" programs typically maintain some independence of law enforcement agencies, since clients often have negative responses to these agencies.

Group strategies have been developed in numerous cities for working with street corner groups to combat delinquency and to treat individual offenders. ${ }^{26}$ Work with street gangs actually began over thirty years ago in Chicago under the direction of Clifford R. Shaw. At that time, emphasis was placed on indigenous leaders and institutions, while today there is greater reliance on professional workers and on involvement of many agencies to coordinate efforts. It is generally assumed that the delinquent behavior of a street corner group is generated by a complex of individual, group, and community forces. The worker's primary goal is generally to

26 For a discussion of different approaches to work with street corner groups, see E. G. Ackley and B. R. Fliegel, "A Social Work Approach to Street Corner Girls," Social Work, October 1960, pp. 27-32; P. Lerman, "Group Work with Youth in Conflict," Social Work, October 1958, pp. 71-78; New York City Youth Board, Reaching the Fighting Gang (New York: New York City Youth Board, 1960); and C. V. Richard, "Finding a Focus for Work with Hostile Youth Groups," in Social Work with Groups (New York: National Association of Social Workers, 1958. . 
modify these forces so that antilegal and antisocial acts will diminish. Other goals include the redirection of behavior into more socially acceptable channels, provision of more satisfying interpersonal relations with peers and adults, vocational counseling, and referral of individuals who require specialized treatment. Beyond the corner group itself, there is sometimes pursued a larger goal, the modification of community conditions so as to enhance legitimate opportunities for delinquents.

Agencies and workers involved in street gang programs have minimal control over many conditions often taken for granted in other correctional agencies. Street gangs are usually well organized at the time of the worker's initial intervention; he can do little to determine the size of the group, background characteristics of members, and changing patterns of participation. He can also achieve only limited regulation of individual and group relations with other groups in the community.

In gang programs the change target and program focus are likely to be more concerned than other correctional agencies are with modifying the group and its social relations. The peer group is the primary target of change. Although the worker attempts to develop meaningful relationships with clients and relies heavily on interpersonal influence, he also seeks to modify group structures and processes so that these will facilitate the attainment of his goals. Thus, he tries to engage the group in less destructive activities, to change its fighting norms, and to weaken authoritarian control by the leaders. He also seeks to modify the group's relations with other groups and with community institutions. ${ }^{27}$ Lerman stresses the importance of translating generalized concepts and directives into more specific practice principles if work with delinquent gangs is to be more effective. Although he believes that social group work services should be primarily directed at individuals and small groups, he emphasizes the need for diagnosis and intervention at the individual, group, or neighborhood level. 28

Although not all personnel in street gang programs are social workers, the basic orientation is that of social group work. Role patterns and techniques of workers are seldom explicitly defined, and great versatility is required.29

Despite some attempts to assess the outcomes of detached worker programs, little information exists on the incidence of law-violating behavior after the worker's activity has been formally terminated. Primary emphasis has been placed on group-level changes, with less concern for assessment of individual problems and characteristics. However, even where priority is assigned to reduction of gang fighting and similar collective disturbances, there remains a concern about individual deviancy and law violation. Thus, Jereczek has recom. mended the formulation of more ob-

27 Walter Miller points out that groups with social group workers achieved a relatively high status vis-à-vis other street corner groups. In addition, group workers were perceived by adolescents differently than other welfare workers or authority" figures. See W. B. Miller, "The Impact of a Community Group Program on Delinquent Corner Groups," Social Service Review, December 1957, pp. 390-406.

28 Lerman, supra note 26.

29 The New York City Youth Board has attempted to identify the characteristic modes of operation in working with street corner groups. $O p$. cit. supra note 26. 
jective indices of delinquency proneness, initially as a basis for individual diagnosis and treatment planning, and later as criteria for evaluation. ${ }^{30}$ Gibbons, too, has argued for differentiated diagnostic models and treatment principles. ${ }^{31}$ Since the ultimate aim of all correctional treatment is stabilized individual change, greater attention to individual characteristics appears necessary.

Both guided group interaction and social group work require explicit use of the group as a means of treatment. Formal descriptions of the former approach assert a marked difference from the latter in the role and task of the worker. ${ }^{32}$ In social group work the worker is much more active in the definition of goals and in the continual manipulation of group conditions to facilitate goal attainment.

\section{Social Milieu Approaches}

Polsky, Grosser, and Ohlin and Lawrence have described some of the negative and unanticipated consequences for juvenile correctional institutions when informal peer relations are ignored, circumvented, or deliberately suppressed by staff. ${ }^{33}$ The informal system cannot be wholly suppressed and, unless it is incorporated as an integral feature of the treatment

30 See G. Jereczek, "Gangs Need Not Be Delinquent," Federal Probation, March 1962, pp. 49-54. Austin has also pointed to the necessity of explicit individual and group goals; see D. Austin, "Goals for Gang Workers," Social Work, October 1957, pp. 43-50.

31 See D. C. Gibbons, "Some Notes on Treatment Theory in Corrections," Social Service Review, September 1962, pp. 295-305.

32 In the actual conduct of "guided group interaction," however, there is evidence that the practitioner also assumes a more central and active role.

33 See Polsky, op. cit. supra note 2, Grosser, supra note 8, and Ohlin and Lawrence, supra note 2. strategy, its pressures will impede rehabilitative efforts. To circumvent this problem, Polsky and others have suggested a basic modification in the organizational structure of authority and in the deployment of professional personnel. This proposal calls for the integration of authority by assigning responsibility for both management and treatment to the professional social worker within each living unit. Such a structure offers greater possibility for coordination of efforts of all staff working directly with clients. Craig and Novick have described the implementation of similar organizational changes in two state training schools. ${ }^{34}$

Our observations suggest that the social group worker, because of his orientation and training, is particularly well qualified for such a position as unit director. ${ }^{35} \mathrm{He}$ is far better equipped to handle the role strains which result from dual responsibility for treatment and management. Ordinarily, when these primary tasks are lodged in separate administrative units, this conflict presses directly on the untrained cottage parent.

One of the seven institutions which we studied over several years made a deliberate effort to restructure the roles and tasks of group workers and

34 See L. P. Craig, "Reaching Delinquents through Cottage Committees," Children, July-August 1959, pp. 129-34; and A. G. Novick, "Training School Organization for Treatment," Proceedings of the National Association of Training Schools and Juvenile Agencies, 1958, pp. 72-80. They also discuss problems of staff acceptance and resistance to the structural modifications.

35 See H. Polsky, "Changing Delinquent Subcultures: A Social Psychological Approach," Social Work, October 1959, pp. 3-15; A. Cohen, "Use of Group Process in an Institution," Social Work, October 1956, pp. 57-61. 
cottage staff in a nuanner similar to that which we have described. ${ }^{36}$ Later observation of the program indicated that the restructuring had positive consequences for staff and clients alike. However, because of long-standing traditions, commitments, and ideologies, such reorganization is not easily accomplished. Furthermore, it requires continuing effort by the executive and the entire staff to maintain a deliberate treatment focus in all facets of the program. Even with foresight and the best intentions, problems arise and unanticipated consequences occur. It is one thing to conceptualize the "therapeutic milieu" and quite another to implement it in the daily operations of an institution!

\section{General Considerations}

Group treatment methods offer no magical solution for the problem of changing legal offenders. On the other hand, each approach seems to present certain advantages when appropriately employed and integrated into a larger agency strategy. The task, then, is to determine more precisely when to employ a specific group method and how to incorporate it into an agency's general design and organization.

The economy of group methods is sometimes argued in their favor. When the objective is simple imparting of information to clients, the use of groups is undoubtedly economical. However, for continuing or intensive treatment, how group and individual treatment procedures compare in costs and staff time has not been sufficiently studied. We are skeptical about assertions that all group treatment methods, when adequately integrated in a

36 Vinter and Janowitz, et al., op. cit. supra note 9 . total treatment strategy, are more economical.

Questions are frequently asked about the types of clients with whom group treatment methods are most ef. fective. Are they more effective with less serious offenders? With chronic offenders? Or with institutionalized clients? There are no definitive answers. Considering the variety of agencies and the broad range of clientele that have received group treatment services, there is little to indicate that such treatment cannot be effective with any type of client under specific conditions and for certain purposes. In evaluative studies where client characteristics have been controlled, consistent relationships have seldom been established between these characteristics and successful or unsuccessful outcomes. Some evidence exists, however, to suggest that group psychotherapeutic methods are ineffective with lower-class delinquents, because these procedures require considerable verbal ability, internalized conflict, and high potential for development of insight about one's attitudes and behavior.

Can group treatment with delinquents be provided by nonprofessionally trained staff; and, if so, under what conditions? Our research and several other evaluative studies suggest that group treatment can best be accomplished by professionals with knowledge of individual and group dynamics and of sociocultural conditions, plus skill in the use of such knowledge with delinquents. Nonprofessional personnel can participate in treatment efforts most effectively under close professional supervision.

The peer group can be employed as a potent means or context for treatment. Sociological theories of delinquency clearly indicate that deliber- 
ate guidance of group forces is necessary if we are to intervene effectively in delinquent subcultures and alter their antisocial attitudes, values, and behaviors. We must challenge the belief that group processes unguided by a skilled worker are somehow self-correcting or that mere participation in a group is therapeutic. We must also point to the limited gains to be achieved when the method is directed only toward group level change, rather than toward stabilized individual change as well. Group treatment under the direction of a skilled worker has much to offer, but the worker must be concerned with both individual and group treatment goals since his ultimate aim is stabilized and transferable change of individual conduct.

One of the most pressing problems throughout the correctional field is the lack of systematic evaluation of existing and emerging programs. The literature is filled with detailed reports of personal experiences; broad generalizations, without valid bases, are frequently made about the applicability of these experiences to other situations. We advocate systematic evaluation in which prestated goals and criteria provide concrete criteria for assessment of change. Programs must be planned and implemented with respect to those goals, and clients assigned randomly or strategically depending upon the controls one can impose. Lastly, there must be specific evaluation of the achievement of deined goals.

\section{Conclusions}

The guidelines we are now able to propose are suggested as conditions which determine the effectiveness of any particular approach selected for implementation. ${ }^{37}$
First, goals must be concretely specified for each client who will receive the service. Only through such specification can the appropriate group method be selected, conducted, and evaluated. Not all goals are equally relevant for every client, and differential client characteristics should not be ignored in planning the effort.

Second, the peer group of clients can be used as an effective means for change, particularly when the behavior or conditions of clients which should be changed are themselves the product of peer group or subculture forces. The potentials of the group can be realized only by deliberate management of group forces and conditions. The conditions and characteristics of the group may operate for or against treatment goals, but their effects can never be neutralized or suppressed. $^{38}$

Third, transactions within the group, if they are to be meaningful, must focus on real client problems and circumstances, as perceived and experienced by the clients. Effective treatment cannot occur where the activities within the group ignore the clients' contemporary life outside the group. Group treatment processes cannot be isolated or segregated from other areas of the client's life.

Fourth, the treatment group will develop as a more powerful means of change as clients can be involved in defining their own change goals, as

37 For a similar set of principles, see $\mathbf{D}$. Cressey, "Changing Criminals: The Application of the Theory of Differential Association," American Journal of Sociology, September 1955, pp. 116-20.

38 See L. McCorkle and R. Korn, "Resocialization within the Walls," The Annals, May 1954, pp. 362-69, for a discussion of some of the problems encountered in implementing a program in a correctional institution. 
they become committed to the change process, and as they can secure significant rewards through their participation. ${ }^{39}$

Fifth, the group treatment effort must be integrated into a larger agency design. It cannot succeed when uncoordinated with other phases of the agency program, or when these are moving in contrary directions. Its success is more likely when additional and indirect means are developed to enhance the forces for change.

Sixth, each of the several group

39 See D. Cartwright and A. Zander (eds.), Group Dynamics: Research and Practice (Evanston, Ill.: Row Peterson, rev. ed., 1960) . Small group research has much to offer today about how group structures and processes can be manipulated and with what effects. treatment methods poses certain requirements for staff knowledge and competence. Those methods which call for specialized training cannot be utilized by persons without such training, except at the risk of adverse consequences.

Seventh, the social milieu approaches present greater problems in design and execution than the direct methods, perhaps greater than an agency can manage at a given time. As we have indicated, however, the direct methods are unlikely to succeed unless certain organizational arrangements can be effected to support them. By and large, the requirements of both direct and indirect methods are the same, and successful treatment is most likely when both approaches are employed. 